\title{
A Quantitative Analysis on the Effect of Varying Nitrate Concentrations on pH levels on the Growth of Algae
}

\author{
Nathaniel Tak ${ }^{1}$, Pranshu Wagh ${ }^{2}$, Sumer Sandhu ${ }^{3}$, Akshay Reddy $^{4}$, Himanshu Wagh ${ }^{5 *}$ \\ ${ }^{1}$ California Northstate University, Rancho Cordova, USA, \\ ${ }^{2}$ Fremont Unified School District, Freemont, USA \\ ${ }^{3}$ California Northstate University, Rancho Cordova, USA \\ ${ }^{4}$ Department of Ophthalmology, California Northstate University, Rancho Cordova, USA \\ ${ }^{5}$ California Northstate University, Rancho Cordova, USA
}

*Corresponding author: Himanshu Wagh, California Northstate University, Rancho Cordova, USA, E-mail: Himanshu. wagh5630@cnsu.edu

\section{ABSTRACT}

Keywords

The objective of this experiment was to determine what nitrate concentration and Algae $\mathrm{pH}$ would provide the most optimal growth for algae. In order to determine this, algae from the American River was taken and grown in solutions with different Nitrate concentrations of nitrate, and $\mathrm{H}+$ ions. It was hypothesized that the algae would grow best in solutions with neutral $\mathrm{pH}$ levels or solutions with high nitrate concentrations. Ions Different amounts of sodium nitrate were added to beakers with similar amounts of water and algae in order to create environments with varying concentrations of nitrate. Different amounts of $\mathrm{NaOH}$ and acetic acid were added to beakers with similar amounts of water and algae in order to simulate environments with varying pH levels.

This experiment was conducted in order to determine how fertilizer runoffs affect algal growth. Fertilizer run offs carry nitrate ions into rivers and lakes, which cause algal blooms to form. It was hypothesized that as the concentration of nitrate increases, the growth rate of the algae would also increase. This is due to the fact that the literature supports the idea that as nitrate is added to rivers and lakes the number of algae present increases. The results from the experiment demonstrated that the most optimal concentration of nitrate in the water for algal growth was in between 1-2 Molar and that the most optimal $\mathrm{pH}$ for algal growth was in between 7-8.

\section{INTRODUCTION}

As a result of the industrial revolution different chemicals were released into the environment and have polluted rivers, lakes, and oceans across the entire world. These pollutants are known to affect the $\mathrm{pH}$ and the nitrate concentration of the water in lakes and rivers.

Pollution if not controlled could drastically decrease the biodiversity on this planet. Maintaining biodiversity is extremely important to humanity's survival as it plays a role in the amount of nutrients and resources that we can use to benefit society. Even though scientists recognize the importance of reducing pollution, society has yet to implement measures to effectively counteract the pollutants created by factories and industries. This pollution has already negatively impacted the ecosystem of various organisms, such as salmon, and has resulted in their populations decreasing across the globe [1]. Therefore, before dumping any chemicals into the rivers, oceans, and lakes of this world it is important to ascertain which substances will harm the organisms in the environment and 


\section{Research Article}

which substances will not harm them. Not only do scientists have the job of understanding how various chemicals affect ecosystems, but they also have the job of figuring out methods to remove harmful pollutants from different environments.

One of the most highly used industrial chemicals that pollute lakes and rivers are fertilizers [2]. Fertilizers are good for crops as they provide them with the nitrogen that they need in order to grow quickly and create large amounts of produce, however they are bad for the wildlife of rivers and lakes during the rain. This is due to the fact that when the terrain of the crops gets wet there is a runoff of soil containing the excess nitrogen that gets deposited into the local lakes and rivers near towns [3]. This excess nitrogen leads to the production of algal blooms within the rivers and lakes [4]. These algal blooms harm both the freshwater and the seawater ecosystems, as they deplete them of oxygen during the night. This depletion of oxygen can lead to drastic decreases for fish populations near the region [4]. Not only do theses algal blooms dramatically reduce the oxygen concentration within these lakes and rivers, they also release very harmful cyanotoxins that can kill off many of the organisms in the environment [5]. These cyanotoxins can be extremely harmful to humans as well if consumed in high amounts. Fertilizers can also be extremely dangerous to the environment as they may cause unintended consequences for the land organisms by altering their biochemistry. Although excess algal blooms are harmful to many organisms, many algae are very important to the ecosystem as they accommodate for about $70 \%$ of oxygen in the atmosphere [6]. Without algae human beings would not be able to survive on this planet. Therefore, it is important to understand how different conditions affect algal growth. Algae tend to flourish and grow faster in temperatures around $20-30{ }^{\circ} \mathrm{C}$ [4]. This organism also tends to flourish in more humid conditions as it needs water as well as warmer temperatures to survive. As it was previously stated high nitrogen levels within in the water are known to cause algal blooms, but it is currently unknown how nitrates within the water quantitatively affect the growth rate of the algae present within it. Drastically changing the $\mathrm{pH}$ can also negatively impact the survivability of organism; therefore, it is also important to understand how $\mathrm{pH}$ affects the survivability of algae within the American River.

Thus, the purpose of this experiment is to quantitatively evaluate how nitrate and $\mathrm{pH}$ levels affect the growth rate of freshwater algae. It is hypothesized that the algae in the solution with the highest nitrate concentration or the most neutral $\mathrm{pH}$ will grow the most. In order to perform the first part of the experiment algae will be masses then placed in solutions with varying $\mathrm{pH}$ levels then massed again in order to determine their growth rate over two weeks. In order to perform the second part of the experiment, a vacuum filtration system and a scale will be used to extract the algae samples and ascertain their initial mass before placing them in their respective solutions. The second part experiment will take about one week's time to generate results that will help determine algal growth rate in environments with varying nitrate

concentrations. Filter paper will also be utilized to ensure that there is a clean collection of the algae before and after it is grown in these different solutions. The data will then be collected and analyzed in order to ascertain whether or not algae growth improves as the nitrate levels in the water increases.

\section{METHODS}

First four water bottles that were filled with algae and river water were obtained. The algae were then filtered out of all four water bottles utilizing filter paper and a vacuum filtration system. The algae were then split into 12 samples of one gram each onto 12 different pieces of filter paper to be used for each of the 12 experimental trials respectively. Next 12 different beakers were set up with $50 \mathrm{ml}$ of water each. Then one gram of algae was added and stirred into to each of the twelve beakers using a glass stir rod. Then 17 grams of $\mathrm{NaNO}_{3}$ were added to two of the beakers, and the beakers were labeled " $4 \mathrm{M}$ trial 1 " and " $4 \mathrm{M}$ trial 2 " respectively. Next

8.5 grams of $\mathrm{NaNO}_{3}$ were added to two of the beakers, and the beakers were labeled " $2 \mathrm{M}$ trial 1" and " $2 \mathrm{M}$ trial 2" respectively. Then 4.25 grams of $\mathrm{NaNO}_{3}$ were added to two of the beakers, and the beakers were labeled " $1 \mathrm{M}$ trial 1 " and “ 1 M trial 2" respectively. Next 2.13 grams of $\mathrm{NaNO}_{3}$ were added to two of the beakers, and the beakers were labeled " $.5 \mathrm{M}$ trial 1" and " $.5 \mathrm{M}$ trial 2" respectively. Then 1.06 grams of $\mathrm{NaNO}_{3}$ were added to two of the beakers, and the beakers were labeled " $4 \mathrm{M}$ trial 1" and " $4 \mathrm{M}$ trial 2" respectively. This procedure was repeated utilizing varying masses of algae and solutions with the $\mathrm{pH}$ levels of 3.03, 7.33, 7.67, and 12.96 . These solutions were created using $1 \mathrm{M}$ acetic acid, river water, tap water, and $1 \mathrm{M} \mathrm{NaOH}$ respectively. All of the beakers were then covered in filter paper and stored in the lab for one week. After the one-week waiting period all of the beakers were filtered and the mass of algae in each beaker

was determined using the weighing scale. Finally, all of the waste was then disposed of in the appropriate waste containers.

\section{RESULTS}

Table 1 demonstrates the initial and final mass of the algae in different solutions of $\mathrm{NaNO}_{3}$ over the course of one week. The growth rate of the algae for each trial can be seen in Table as well. The masses of the algae were weighed before the trial utilizing a scale. The algae were dark green when it was in a condensed form, but when the algae were placed in solution its 
color was light green. Although attempts were made to keep the initial masses for every trial at $1.00 \mathrm{~g}$, this did not happen due to instrumental error.

Table 2 portrays the average growth rate for the algae in solutions with varying concentrations of $\mathrm{NaNO}_{3}$. The average growth rate values reported in Table 2 were obtained utilizing

Table 1. Algae Growth Rate and Algae Mass Per Trial

\begin{tabular}{|l|c|c|c|}
\hline Trial & $\begin{array}{c}\text { Initial Mass } \\
\text { of Algae }\end{array}$ & $\begin{array}{c}\text { Final Mass } \\
\text { of Algae }\end{array}$ & $\begin{array}{c}\text { Growth } \\
\text { Rate of } \\
\text { Algae }\end{array}$ \\
\hline $4 \mathrm{M}$ NaNO3 (Trial 1) & $1.02 \mathrm{~g}$ & $1.24 \mathrm{~g}$ & $.0314 \mathrm{~g} /$ day \\
\hline $4 \mathrm{M} \mathrm{NaNO3}$ (Trial 2) & $.98 \mathrm{~g}$ & $1.21 \mathrm{~g}$ & $.033 \mathrm{~g} /$ day \\
\hline $2 \mathrm{M} \mathrm{NaNO3}$ (Trial 1) & $1.04 \mathrm{~g}$ & $1.43 \mathrm{~g}$ & $.0557 \mathrm{~g} /$ day \\
\hline $2 \mathrm{M} \mathrm{NaNO3}$ (Trial 2) & $.98 \mathrm{~g}$ & $1.50 \mathrm{~g}$ & $.074 \mathrm{~g} /$ day \\
\hline $1 \mathrm{M}$ NaNO3 (Trial 1) & $1.02 \mathrm{~g}$ & $1.54 \mathrm{~g}$ & $.074 \mathrm{~g} /$ day \\
\hline $1 \mathrm{M}$ NaNO3 (Trial 2) & $.97 \mathrm{~g}$ & $1.49 \mathrm{~g}$ & $.074 \mathrm{~g} /$ day \\
\hline $.5 \mathrm{M} \mathrm{NaNO3} \mathrm{(Trial} \mathrm{1)}$ & $.96 \mathrm{~g}$ & $1.45 \mathrm{~g}$ & $.070 \mathrm{~g} /$ day \\
\hline $.5 \mathrm{M}$ NaNO3 (Trial 2) & $.98 \mathrm{~g}$ & $1.44 \mathrm{~g}$ & $.066 \mathrm{~g} /$ day \\
\hline $.25 \mathrm{M}$ NaNO3 (Trial 1) & $1.07 \mathrm{~g}$ & $1.39 \mathrm{~g}$ & $.0457 \mathrm{~g} /$ day \\
\hline $.25 \mathrm{M}$ NaNO3 (Trial 2) & $.99 \mathrm{~g}$ & $1.31 \mathrm{~g}$ & $.046 \mathrm{~g} /$ day \\
\hline River water (Trial 1) & $1.02 \mathrm{~g}$ & $1.24 \mathrm{~g}$ & $.0314 \mathrm{~g} /$ day \\
\hline River water (Trial 2) & $1.00 \mathrm{~g}$ & $1.21 \mathrm{~g}$ & $.0300 \mathrm{~g} /$ day \\
\hline
\end{tabular}

Table 2. Average Algae Growth Rate for Varying Concentrations of $\mathrm{NO}_{3}^{-}$

\begin{tabular}{|l|c|}
\hline Concentration of $\mathrm{NO}_{3}^{-}$ & $\begin{array}{c}\text { Average Growth Rate of } \\
\text { Algae }\end{array}$ \\
\hline $4 \mathrm{M}$ & $.032 \mathrm{~g} /$ day \\
\hline $2 \mathrm{M}$ & $.065 \mathrm{~g} /$ day \\
\hline $1 \mathrm{M}$ & $.074 \mathrm{~g} /$ day \\
\hline $.5 \mathrm{M}$ & $.068 \mathrm{~g} /$ day \\
\hline $.25 \mathrm{M}$ & $.0458 \mathrm{~g} /$ day \\
\hline $0 \mathrm{M}$ (River water) & $.0307 \mathrm{~g} /$ day \\
\hline Overall Change & $.0526 \mathrm{~g} /$ day \\
\hline Standard deviation & .00453 \\
\hline
\end{tabular}

the information provided by Table 1 . The solution with a 0 $\mathrm{M}$ of $\mathrm{NO}_{3}^{-}$ions had the least average algal growth of .0307 $\mathrm{g}$ /day. The solution with a $1 \mathrm{M}$ of $\mathrm{NO}_{3}^{-}$ions had the highest algal growth of $.074 \mathrm{~g} /$ day. The average growth rate of algae was measured by grams of increased mass per day. The overall average change in mass and the standard deviation for the various growth rates in the nitrate trials are also reported in Table 2.

Table 3 displays the raw data of the masses of each of the beakers that were recorded. The initial masses of the beakers vary due to the fact that different beaker types were used in the experiment, however they contained the same volume of solution to the mass of the beaker didn't skew the results. The data in Table 3 portrays the masses of all of the trials for the river water, the tap water, the acetic acid solution, and the $\mathrm{NaOH}$ solution pre and post the two- week waiting process. Table 3 also shows the change of mass for each individual trial over the waiting period.

Table 4 displays the processed data which shows the average mass loss or gain depending on the environment that the algae were placed in. Additionally, the $\mathrm{pH}$ of the different environments was also recorded in the table. The algae grew the most, as indicated by the fact that the river environment produced the highest increase in mass for the algae and survived the best in the slightly basic river water which is most similar to its normal habitat. The overall average change in algal mass and standard deviation for all solutions in the $\mathrm{pH}$ trials was also reported in Table 4. The algae survived the worst in the highly acidic environment; this can be seen from the relatively large decrease in mass exhibited by the algae in the acidic environment.

Figure 1 displays the growth rate of algae in solutions with different concentrations of nitrate. The concentration of nitrate was measured in Molarity. The growth rate of the algae was measured in grams/day. The graph has a relative maximum growth rate somewhere in between 1 and 2 Molar $\mathrm{NO}_{3}^{-}$. The graph is very parabolic in nature meaning that there is no definite slope of this graph. The graph in Figure 1 was created from the data provided by Table 2 .

Figure 2 displays the growth rate of algae in solutions with different concentrations of $\mathrm{H}^{+}$ions. The concentration of $\mathrm{H}^{+}$ions was measured in $\mathrm{pH}$. The growth rate of the algae was measured

Table 3. Masses of the beakers in grams pre and post 2 week waiting period

\begin{tabular}{|c|c|c|c|c|c|c|c|c|}
\hline & $\begin{array}{c}\text { River } \\
\text { trial } 1\end{array}$ & $\begin{array}{c}\text { River } \\
\text { trial } 2\end{array}$ & $\begin{array}{c}\mathrm{NaOH} \\
\text { trial } 1\end{array}$ & $\begin{array}{c}\mathrm{NaOH} \\
\text { trial } 2\end{array}$ & $\begin{array}{l}\text { Acetic } \\
\text { trial } 1\end{array}$ & $\begin{array}{l}\text { Acetic } \\
\text { trial } 2\end{array}$ & $\begin{array}{c}\text { Tap } \\
\text { trial } 1\end{array}$ & $\begin{array}{c}\text { Tap } \\
\text { trial } 2\end{array}$ \\
\hline Pre- 2 week wait period mass of beakers (grams) & 209.35 & 276.74 & 211.51 & 209.33 & 159.55 & 266.04 & 265.24 & 268.21 \\
\hline Post 2 week wait period mass of beakers (grams) & 212.5 & 278.03 & 208.97 & 207.53 & 154.37 & 261.81 & 267.34 & 269.56 \\
\hline Change in mass (grams) & 3.15 & 1.29 & -2.54 & -1.80 & -5.18 & -4.23 & 2.10 & 1.35 \\
\hline
\end{tabular}




\section{Research Article}

Table 4. How the masses of the algae were affected by the $\mathrm{pH}$ of their environment.

\begin{tabular}{|l|c|}
\hline Type of Solution & $\begin{array}{c}\text { Average change in mass } \\
\text { within } 2 \text { weeks }\end{array}$ \\
\hline Acetic acid solution $(\mathrm{pH}=3.03)$ & $-4.71 \mathrm{~g}$ \\
\hline Tap water $(\mathrm{pH}=7.67)$ & $1.73 \mathrm{~g}$ \\
\hline River water $(\mathrm{pH}=7.33)$ & $2.22 \mathrm{~g}$ \\
\hline $\mathrm{NaOH}$ solution $(\mathrm{pH}=12.96)$ & $-2.17 \mathrm{~g}$ \\
\hline Overall change & $-.73 \mathrm{~g}$ \\
\hline Standard deviation & .32 \\
\hline
\end{tabular}

\section{Algae Growth Rate vs Molarity of} Nitrate

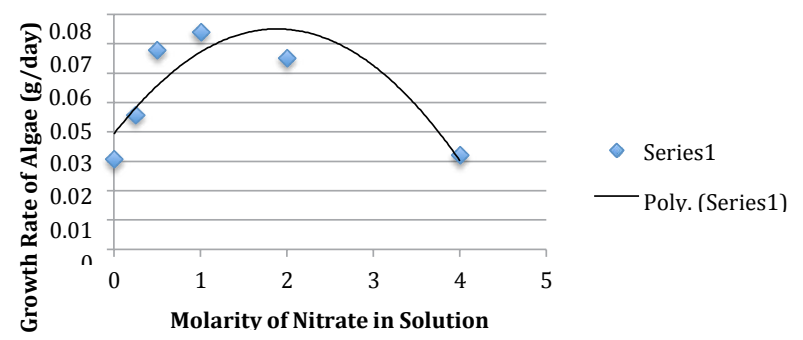

Figure 1. Graph of Growth Rate of Algae vs. Molarity of $\mathrm{NO}_{3}^{-}$in Solution

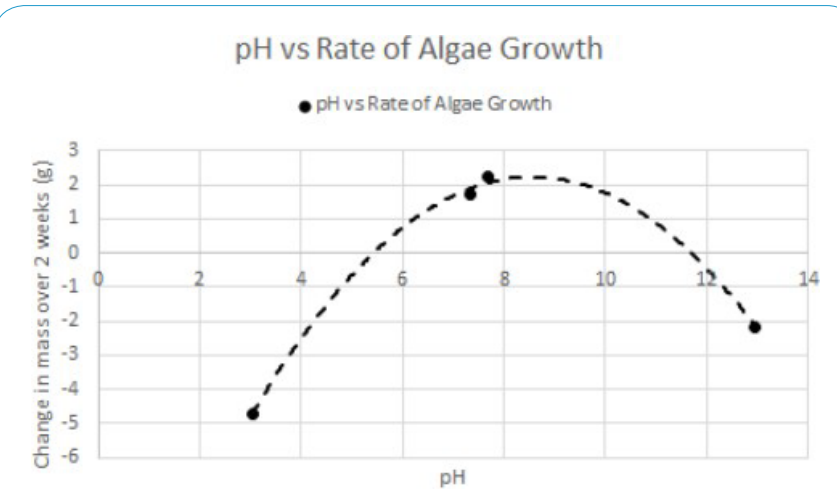

Figure 2. Graph of Algal Growth Rate vs $\mathrm{pH}$ of Solution

in overall change in mass over 2 weeks. The graph has a relative maximum growth rate somewhere in between the $\mathrm{pH}$ levels of 7 and 8 . The graph is very parabolic in nature meaning that there is no definite slope at any point on this graph. Table 4 provided the data used to create the graph in Figure 2.

\section{DISCUSSION}

Algal blooms, which are considered hazardous to many freshwater ecosystems, are caused by run-offs from fertilizers that carry nitrates into these waters [2]. Algal blooms are considered to be highly toxic to the environment as they deplete waters of oxygen and introduce cyanotoxins to the creatures in these areas [4]. Pollutants from factories such as nitrogen dioxide can cause acid rain and drastically change the $\mathrm{pH}$ of freshwater ecosystems [3]. This can negatively affect the survivability of organisms that need a specific $\mathrm{pH}$ level in order to survive.

The purpose of this lab was to find out how concentrations of $\mathrm{H}^{+}$and $\mathrm{NO}_{3}^{-}$in the water affect the growth rate of algae within the American River. The purpose of this lab was achieved as both the optimal $\mathrm{pH}$ and nitrate levels were determined for algal growth. It was hypothesized that algae would grow best the solutions with the highest nitrate concentration or the solutions with the most neutral $\mathrm{pH}$ levels. This hypothesis was proven to be partially nullified as it was found that there was a threshold of around $1 \mathrm{M}$ of nitrate that was the best for algal growth, however past that threshold the growth of the algae started to decline. The hypothesis was also proven to be partially true as it was also discovered that there was a threshold $\mathrm{pH}$ level around 7 that was the most optimal for algal growth. This could mean that there is an optimal level of nitrogen in the water for the growth of algae, and that when this threshold is met the consequences for the marine life organisms are the most severe.

The data provided in Figure 1 suggests that there is an optimal concentration of nitrate ions in solution for algal growth. Based off the graph in Figure 1, it was determined that the most optimal concentration for algal growth was in between 1-2 molar. The data from Figure 1 also supports the idea that as nitrate concentration dramatically increases or decreases from this optimal threshold of $1-2 \mathrm{M}$ the growth rate of the algae dramatically decreases. The solution with the lowest overall algal growth was the solution with a nitrate concentration of $0 \mathrm{M}$. This was the solution of water that was taken from the American River. This could indicate that fertilizer run offs have not yet had a dramatic impact on the freshwater ecosystem within the American River. The graph provided in Figure 2 suggests that the optimal $\mathrm{pH}$ level for algal growth is in between 7 and 8 . The solution that had the most algal growth was the river water, which had a $\mathrm{pH}$ of around 7.33. This could indicate that a significant amount of acidic waste has not been dumped in the American River.

The percent error calculated for the nitrate growth trials and $\mathrm{pH}$ growth trials were relatively high at $136 \%$ and $41.6 \%$ respectively. This is most likely due to random error as not enough trials were run to determine the algal growth rate. In order to avoid this discrepancy from occurring again, more trials need to be run to get a more accurate value for the algal growth rate. This error could also be attributed to systematic flaws that were caused by losing the mass from obtaining the 
algae through the filter paper. If the algae were immediately placed on the weigh boat after being filtered instead of being left to dry out on the filter paper, then less mass could have been lost and the error would have been reduced. Future research with this topic could potentially explore how other factors such as metallic waste affects the growth and survivability of algae.

The broader impact of this research is that it can be utilized to understand how different pollutants can negatively impact the organisms within an area and dramatically ruin ecosystems. This investigation also displays the conditions that are necessary to create the most ideal culture media for algae. Scientists will also be able to utilize this research to determine the safe $\mathrm{pH}$ and nitrate levels when they decide to grow algae for research or when conducting various experiments on the algae. Algae farmers that want to ensure the maximum algal growth for the cheapest price possible can also utilize this research by creating solutions with the most optimal $\mathrm{pH}$ levels and nitrate concentrations.

\section{CONCLUSION}

The purpose of this lab was to determine the optimal $\mathrm{pH}$ levels and nitrate concentration for algal growth. It was hypothesized that the algae would grow optimally in the solution that had the highest nitrate concentration or in the solution with the most neutral ph. The purpose of this experiment was achieved, but the hypothesis was partially nullified, as it was determined through the lab that the optimal $\mathrm{pH}$ for algal growth was around 7 , and that the optimal nitrate concentration was in between 1-2 M. This experiment was conducted as data from the literature suggested that $\mathrm{pH}$ and $\mathrm{NO}_{3}{ }^{-}$concentrations would have an effect on the growth rates of algae. The broader impact of this research is that it shows how pollution from fertilizer runoffs and acidic waste can eventually ruin the freshwater ecosystem of the American River if there is no environmental control.

\section{REFERENCES}

1. Lundin JI, Spromberg JA, JorgensenJC, Myers JM, Chittaro PM, et al. (2019) Legacy habitat contamination as a limiting factor for Chinook salmon recovery in the Willamette Basin, Oregon, USA. Plos One, 14(3), 1-21.

2. Wera A, Ling TY, Nyanti L, Sim SF, Grinang J (2019) Effects of Opened and Closed Spillway Operations of a Large Tropical Hydroelectric Dam on the Water Quality of the Downstream River.Journal of Chemistry, 19, 1-11.

3. Wang J, Zheng B, Kang X, Yu H, Li D, et al. (2018) Diel Variation of Water Inorganic Nitrogen and Phosphorus during Algal Blooms. Polish Journal of Environmental Studies, 28(2), 867-875.

4. Birbeck J, Westrick J, O’Neill G, Spies B, Szlag D (2019) Comparative Analysis of Microcystin Prevalence in Michigan Lakes by Online Concentration LC/MS/MS and ELISA.Toxins, 11(1), 1-13.

5. Savadova K, Mazur-Marzec H, Karosienė J, Kasperovičienė J, Vitonytė I, et al. (2018) Effect of Increased Temperature on Native and Alien Nuisance Cyanobacteria from Temperate Lakes: An Experimental Approach Toxins, 10(11), 444-461.

6. Nedelcu A, Popa L, Gageanu I, Pruteanu A (2018) Research on Algae Growing in Open System with Cascade-Type Installation. International Scientific Conference, 2, 412-418. 